\title{
Necessity of Grammar Teaching
}

\author{
Jianyun Zhang \\ China Agricultural School \\ Xingtai 054000, China \\ Tel: 86-535-233-7565 E-mail: zhangjianyun321@163.com
}

\begin{abstract}
Grammar is often misunderstood in the language teaching field. The misconception lies in the view that grammar is a collection of arbitrary rules about static structures in the language. Further questionable claims are that the structures do not have to be thought, learners will acquire them on their own, or if the structures are taught, the lessons that ensue will be boring. This thesis on comparative approach tries to make a brief analysis of necessity of grammar teaching before it gives a relatively objective description of its function and significance in language teaching. It argues that, grammar teaching is necessary in language teaching.
\end{abstract}

Keywords: Grammar, English language teaching, Necessity

\section{Attitudes to grammar}

Many language authorities have different attitudes to grammar. In 1622 a certain Joseph webbe, schoolmaster and textbook writer, 'No man can run speedily to the mark of language that is shackled---with grammar precepts.' He maintained that grammar could be picked up though simply communicating: 'By exercise of reading, writing, and speaking---all things belonging to Grammar, will without labour, and whether we will or not, thrust themselves upon us.'

Webbe was one of the earliest educators to question the value of grammar instruction, but certainly not the last. In fact, no other issue has so preoccupied theorists and practitioners as the grammar debate, and the history of language teaching is essentially the history of the claims and counterclaims for and against the teaching of grammar. Differences in attitude to the role of grammar underpin differences between methods, between teachers, and learners. It is a subject that everyone involved in language teaching and learning has an opinion. And these opinions are often strongly and uncompromisingly stated. Here, for example, are a number of recent statements on the subject:

'There is no doubt that a knowledge-implicit or explicit—of grammatical rules is essential for the mastery of a language.'

[Penny Ur, a teacher trainer, and author of Grammar Practice Activities]

'Grammar is not the basis of language acquisition, and the balance of linguistic research clearly invalidates any view to the contrary.'

[Michael Lewis, a popular writer on teaching methods]

But I will take an entrenched position to make up my own minds: grammar teaching is essential in language teaching field. Grammar rules like the molds of the parts of a machine, without them, workers can only stand by the iron-water. Similarly, English language learners who have been lacking in grammar rules instruction can neither use English language accurately to make a complete sentence, nor speak English language fluently on accuracy.

\section{Necessity of grammar teaching}

It is exact that putting grammar in the foreground in second language teaching, because language knowledge of grammar and vocabulary is the base of English language. Grammatical competence is one of communicative competence. Communicative competence involves knowing how to use the grammar and vocabulary of the language to achieve communicative goals, and knowing how to do this in a socially appropriate way. Communicative goals are the goals of learners' studying English language. So grammar teaching is necessary to achieve the goals.

\subsection{Grammar teaching is essential}

According to the dictionary definition, there are at least two senses of the word grammar, (1)[U] study or science of, rules for, the combination words into sentences(syntax), and the forms of words (morphology). (2) [C] book containing the rules of grammar of a language. Language teaching is generally concerned with the former---uncountable---meaning of grammar. That is, grammar as a system of rules (or patters) which describe the formation of a language's sentences. 
Grammar is not simple a thing. It is something that---in certain condition ---happens. To use an analogy: an omelette is the product of a (relatively simple but skillful) process involving the beating and frying of eggs. The process and the product are clearly two quite different things, and we could call one making an omelette and the other an omelette. Similarly, the grammar is the result of a process. We need to maintain a distinction between the product and its process of creation.

To take the analogy one step further: to someone who had never seen an omelette being made, it might be difficult to infer the process from the product. They would be seriously mistaken if they thought that making an omelette was simply a case of taking a lot of little bits of omelette and sticking them together. So was the grammar. What you see and how it came to be that way are two quite different things. It would be naïve to suppose that the fluid production of a sentence like If I'd known you were coming, I would have baked a cake results from the cumulative sticking together of individual words or even of individual grammatical structures. The same goes for the way we learn languages. Inferring the process of language acquisition from its product (grammar) is like inferring the process of "omeletting" from the omelette. Or, for that matter, inferring the chicken from the egg.

The language teaching equivalent is: I, the teacher, will cut the language into lots of little pieces---called grammar---so that you, the learner, will be able to reassemble them in real communication. Thus: conjunction if + subject pronoun +past perfect (consisting of past auxiliary had + past participle), followed by nominal that---clause, consisting of---etc, etc. what happens, of course, is that learners take these little bits of grammar description and try to stick them together, and then wonder why they can produce sentences like If I'd known you were coming, I would have baked a cake. It ignores the fact that the product and the process are two quite different things. So grammar (the product) ought to be taught. During the teaching process, the learner will take care of the process and understand why they can produce sentences like If I'd known you were coming, I would have baked a cake.

\subsection{Grammar is not acquired naturally; it needs be taught}

It is true that some learners acquire second language grammar naturally without instruction. For example, there are immigrants to the United States who acquire proficiency in English on their own. This is especially true of young immigrants. However, this is not true for all learners, particularly the learners in China. We have no English surroundings. It is very difficult that studying English on our own. Though highly motivated learners with a particular aptitude for languages may achieve a degree of proficiency without any formal instruction, but whose English is far from accurate. An important question is that it is possible with grammar instruction to help learners who cannot achieve accuracy in English on their own. And more often 'pick it up as you go along' learners reach a language plateau beyond which it is very difficult to progress. To put it technically, their linguistic competence fossilizes. Research suggests that learners who receive no instruction seem to be at risk of fossilizing sooner than those who do receive instruction.

It is also true that learning particular grammatical distinctions requires a great deal of time even for the most skilled learners but another important question is that it is possible to accelerate students natural learning of grammar through instruction. As of the recent popular Communicative Approach, it has false ideas that thinking the grammar is acquired virtually unconsciously, and studying the rules of grammar is simply a waste of valuable time. But research finds that subjects who received grammar instruction progressed to the next stage after a two-week period, a passage normally taking several months in untutored development. Though the number of subjects studied was small, the finding provides evidence of the efficacy of grammar teaching over leaving acquisition to run its natural course.

Grammar instruction can help learners acquire grammar they would not have learned on their own, some research points to the value of grammar instruction to improve learners' accuracy.

\subsection{Grammar is a collection of meaningful forms}

Many people associate the term grammar with verb paradigms and rules about linguistic form. They think grammar is unidimensional and meaningless. However, grammar is not like this. It embodies the three dimensions of form, meaning and use. As can be seen in the pie chart in Figure 1, these dimensions are interdependent; a change in one results in change in another. Despite their interdependence, however, they each offer a unique perspective on grammar. For example, the passive voice in English clearly has its form. It is composed of a form of the be verb and the past participle. Sometimes it has the preposition by before the agent in the predicate: (1) The bank was robbed by the same gang that hijacked the armored car. That the passive can occur only when the main verb is transitive is also part of its formal description.

The passive voice has a grammatical meaning. It is a focus construction, which confers a different status on the receiver or recipient of an action than it would receive in the active voice. For example, the bank in sentence (1) is differently focused than it would be in the active sentence: (2) The same gang robbed the bank.

When or why do we use the passive voice? In such cases when the receiver of the action is the theme or topic, when we do not know who the agent is, when we wish to conceal the identity of the agent, when the agent is obvious and easily derivable from the context, when the agent is redundant, and so on. 
To use the English passive voice accurately, meaningfully, and appropriately, the second language students must master all three dimensions. This is true of any grammatical structure.

\subsection{Grammar is not a collection of arbitrary rules}

Some people think that grammar is a collection of arbitrary rules. In fact it is not. While there is some synchronic arbitrariness to grammar, not all of what is deemed arbitrary is so. If one adopts a broad enough perspective, it is possible to see why things are the way they are. For example, the following sentences: (3) There is the book missing. (4) There is a book missing.

Grammar books will say that sentence (3) is ungrammatical because sentences with existential there almost always take an indefinite noun phrase in the predicate. Why? The reason is not arbitrary. There used to introduce new information, and the preferred position for new information is toward the end of a sentence. A noun phrase that contains new information is marked by the use of the indefinite article, $a$ or an, if it is a singular common noun, as in sentence (4).

\section{The cases for grammar}

There are two kinds of attitudes to grammar: one, for grammar, the other, against grammar. My attitude is for grammar, it ought to be put in the foreground in second language teaching.

\subsection{Grammar is the sentence - making machine}

Part of process of language learning must be what is sometimes called item-learning ------that is the memorization of individual items such as words and phrases. However, there is a limit to the number of items a person can both retain and retrieve. Even travelers' phrase books have limited usefulness-good for a three-week holiday, but there comes a point where we need to learn some patterns or rules to enable us to generate new sentence. That is to say, it is grammar. Grammar, after all, is a description of the regularities in a language, and knowledge of these regularities provides the learner with the means to generate a potentially enormous number of original sentences. The number of possible new sentences is constrained only by the vocabulary at the learner's command and his or her creativity. Grammar is a kind of 'sentence-making machine'. It follows that the teaching of grammar offers the learner the means for potentially limitless linguistic creativity.

\subsection{Grammar is the advance-organiser}

The linguist Stephen Krashen makes the distinction between learning and acquisition. Learning, according to Krashen, results from formal instruction, typically in grammar, and is of limited use for real communication. Acquisition is a natural process: it is the process by which the first language is picked up, and by which other languages are picked up solely through contact with speakers of those language. Success in a second language is due to acquisition, not learning, moreover, he claims that learnt knowledge can never become acquired knowledge. However, the researcher Richard Schmidt kept a diary of his experience learning Portuguese in Brazil. Initially he had enrolled in formal language classes where there was a heavy emphasis on grammar. When he left these classes to travel in Brazil his Portuguese made good progress, a fact he attributed to the use he was making of it. However, as he interacted naturally with Brazilians he was aware that certain features of the talk---certain grammatical items---seemed to catch his attention. He noticed them. It so happened that these items were also items he had studied in his classes. What's more, being more noticeable, these items seemed to stick. Schmidt concluded that noticing is a prerequisite for acquisition. The grammar teaching he had received previously, while insufficient in itself to turn him into a fluent Portuguese speaker, had primed him to notice what might have gone unnoticed, and hence had indirectly influenced his learning. It had acted as a kind of advance organizer for his later acquisition of the language. I think this is also with learning English language.

\subsection{Grammar teaching is the rule-of-law}

Grammar is a system of learnable rules, it lends itself to a view of teaching and learning known as transmission. A transmission view sees the role of education as the transfer of a body of knowledge from those that have the knowledge to those that do not. Such a view is typically associated with the kind of institutionalized learning where rules, order, and discipline are highly valued. Many learners come to language classes with fairly fixed expectations to what they will do there. These expectations may derive from previous classroom experience of language learning. They may also derive from experience of classroom in general where (traditionally, at least) teaching is of the transmission kind. On other hand, their expectations that teaching will be grammar-focused may stem from frustration experienced at trying to pick up a second language in a nonclassroom setting, such as through self-study, or through immersion in the target language culture. Such students may have enrolled in language classes specifically to ensure that the learning experience is made more efficient and systematic.

\section{Conclusion}

The value of grammar teaching is important in English language teaching field. Grammar is the base of English language. It is not acquired naturally, but learning, it needs be instructed. Grammar operates at the sentence level and governs the syntax or word orders that are permissible in the language. It also works at the subsentence level to govern 
such things as number and person agreement between subject and verb in a sentence. To grammar learning, some students may have a more analytical learning style than others, but if one hope to use English language accurately and fluently, it is necessary for him to receive grammar rules instruction. Grammar is not different from anything else, it is likely that students will learn at different rates.

In a short word, grammar teaching is necessary in English language teaching.

\section{References}

Fangjie zhang. (1993). Oxford Advanced Learner's Dictionary of Current English with Chinese Translation. Beijing: The Commercial Press, Oxford University Press.

Guowen Huang. (2000). "Communicative Competence and Communicative Language teaching". Foreign Language Teaching \& Research in Basic Education, 1, 30.

Jian zhang. (2006). "Laying Equal Stress on Listening and Speaking with Top Priority to the Latter". Computer-assisted Foreign Language Education, 5, 56.

Larsen-Freeman,D. (1995). On the teaching and learning of grammar: Challenging the myths. In F.Eckman et al. (Eds), Second language acquisition theory and pedagogy, Mahwah, NJ: Lawrence Erlbaum.

Pienemann, M. (1984). Psychological constraints on the teachability of languages [A]. Studies in Second language acquisition, 6, 186-214.

Scott, Thornbury. (2001). "Why Teach Grammar". Foreign Language Teaching \& Research in Basic Education, 1, 51-54.

Scott,Thornbury. (2003). "Grammar as Process". Foreign Language Teaching \& Research in Basic Education, 3, 48-49.

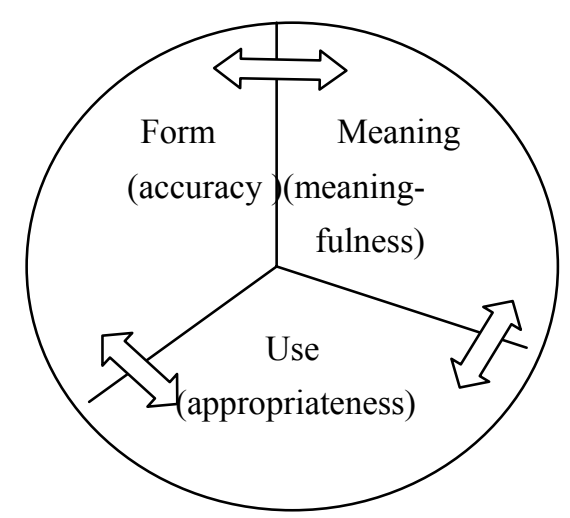

Figure 1 